\title{
Behavioral disorders as unusual presentation of pediatric extraventricular neurocytoma: report on two cases and review of the literature
}

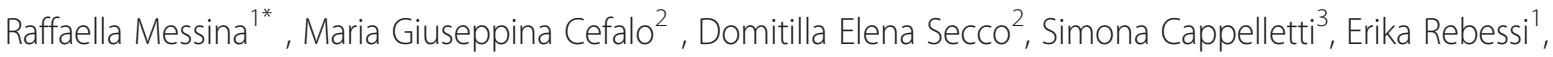 \\ Andrea Carai ${ }^{1}$, Giovanna Stefania Colafati ${ }^{4}$, Francesca Diomedi Camassei ${ }^{5}$, Antonella Cacchione ${ }^{2}$, \\ Carlo Efisio Marras ${ }^{1}$ and Angela Mastronuzzi ${ }^{2}$
}

\begin{abstract}
Background: Extraventricular neurocytomas (EVNs) are rare parenchymal brain tumors, distinct from central neurocytomas that are typically located within the supratentorial ventricular system. Seizures and headache represent the most common symptoms of extraventricular neurocytomas in the cerebral hemisphere both in adult and pediatric population.

Case presentation: We describe two cases of pediatric EVN with clinical onset characterized by behavioral and attention deficit/ hyperactivity disorders. The association between behavioral/attention disorders in childhood and the presence of a frontal neurocytoma has never been described before. Furthermore, inappropriate levels of inattention, hyperactivity and impulsivity are common among the neurobehavioral and developmental disorders in childhood. We reviewed 43 pediatric cases of extraventricular neurocytoma included in the PubMed database and their clinical presentation, and we never found this unusual relationship.

Conclusion: In childhood, the attention/hyperactivity disorders seem to be often over-diagnosed. When these deficits are more subtle and do not well-fit in a specific neurocognitive disorder, the clinicians should have a suspicion that they might mask the clinical features of a frontal lesion. This paper is focused on the clinical presentation of the extraventricular neurocytoma and the possible organic etiology of an attention and hyperactivity deficit.
\end{abstract}

Keywords: Extraventricular neurocytoma, Pediatric brain tumors, Behavioral disorder, Attention deficit/hyperactivity disorders

\section{Background}

Extraventricular neurocytoma (EVN) is a parenchymal brain tumor distinct from central neurocytoma. It is most commonly located in the frontal and parietal lobes [1] and included in the 2007 World Health Organization (WHO) classification of tumors of the central nervous system [2].

Although the incidence of EVN in childhood is not known, it is certainly a rare tumor. It is composed by either glial or neuronal cell differentiation. EVNs have

\footnotetext{
* Correspondence: raffaella.messina@opbg.net

Equal contributors

'Department of Neuroscience and Neurorehabilitation, Neurosurgery Unit, Bambino Ges Children s Hospital, IRCCS, Piazza Sant Onofrio 4, 00165 Rome, Italy

Full list of author information is available at the end of the article
}

a potential aggressive behavior based on the MIB-1 labeling index $(>3 \%)$ and on atypical histological features. They are mostly confused with oligodendrogliomas or ependymomas [3]. Clinical symptoms are usually dependent on side and size tumor. Partial seizures and headache represent the most frequent clinical presentation of EVN. Even though the EVNs are commonly located in the frontal lobe, behavioral or cognitive development disorders have never been described as presentation symptoms.

\section{Methods}

Written informed consent was obtained from the patients parents for publication of this Case report and any accompanying images. We report on two cases of extraventricular neurocytoma in two children referred to the 

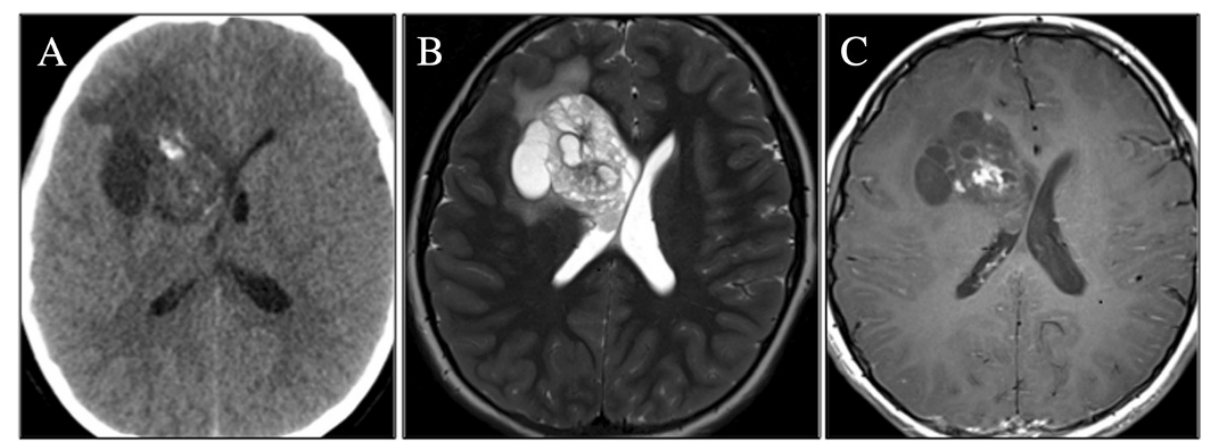

Figure 1 Patient 1: head CT scan and brain MRI, axial images. (A) CT scan: large, calcified and heterogeneous round mass in the right frontal lobe, with hyperdense spots and edema surrounding the lesion; (B) MR T2 weighted images: enhancing lobulated mass with microcystic and solid components; (C) Contrast-enhanced image: inhomogeneous patchy enhancement of the lesion.

Neuropsychiatry Unit of Bambino Ges Children s Hospital in Rome with the diagnosis of attention deficit/ hyperactivity disorder (ADHD). We further reviewed 43 pediatric cases of EVN included in the PubMed database with particular reference to onset symptoms.

\section{Case presentation}

\section{Patient 1}

A 10-year-old male, with a clinical diagnosis of ADHD since he was 7-year-old, was admitted to our Hospital with persistent headache and vomiting. Physical examination showed bilateral papilloedema. No other neurological signs were evident. Non-enhanced brain CT scan documented a large $(4.5 \mathrm{~cm})$, calcified and heterogeneous round mass in the right frontal lobe with vasogenic edema. Brain MRI confirmed an enhancing lobulated mass with micro-cystic and solid components, causing a right-to-left shift and disappearance of the frontal horn of the right ventricle (Figure 1). The patient underwent a gross total resection of the lesion with a histological diagnosis of ventricular neurocytoma (WHO Grade II). A monomorphous neoplasia composed of small, round synaptophysin-positive cells with uniform distribution was observed, with a very low proliferation rate (1-2\%); GFAP staining showed the presence of scattered reactive astrocytes (Figure 2). The patient recovered well, showing a resolution of raised intracranial pressure symptoms and remaining neurologically intact with a progressive reduction of affective problems, attention deficit and anxiety disorders.

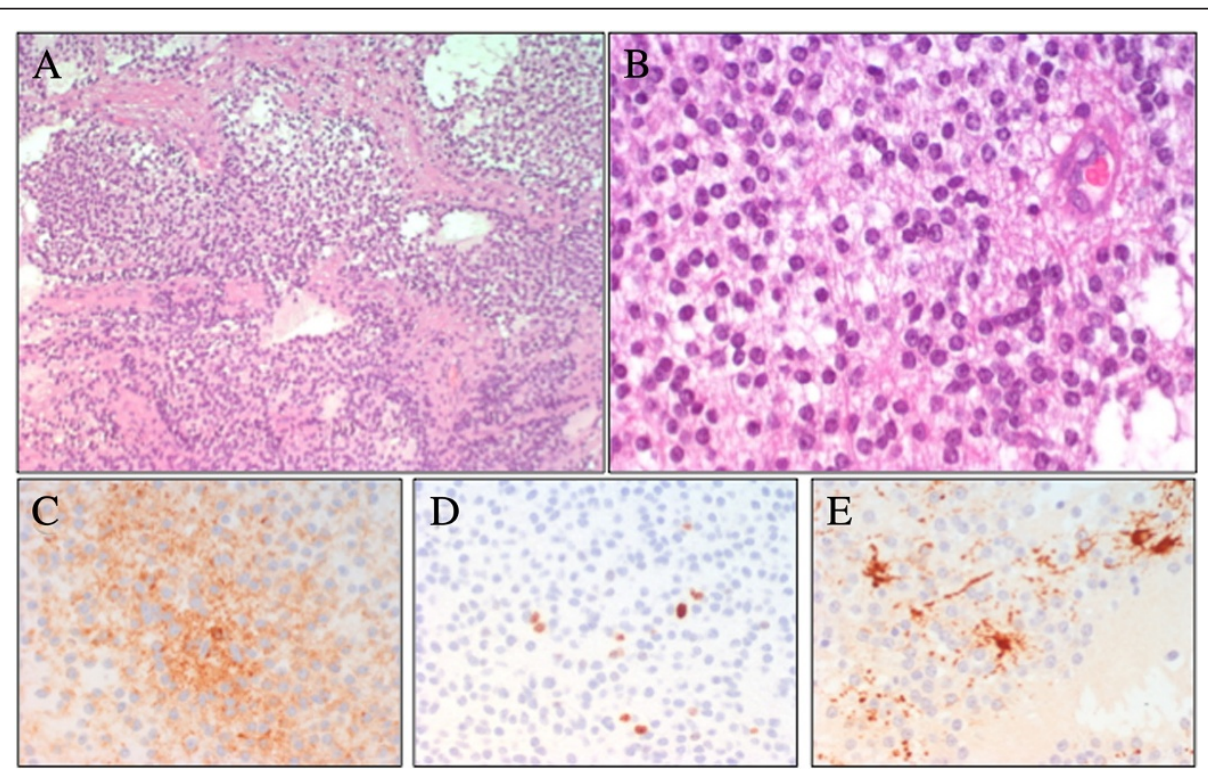

Figure 2 Patient 1: photomicrographs of the extraventricular neurocytoma. Specimens showing: (A-B) the uniform population of round $\begin{array}{llll}\text { cells (hematoxylin and eosin } 20 & \text { 40), with synaptophysin-positive cells } & \text { (C). Photomicrographs of (D) low immunoreactivity to Ki-67 and }\end{array}$ (E) GFAP stain marked scattered reactive astrocytes. 


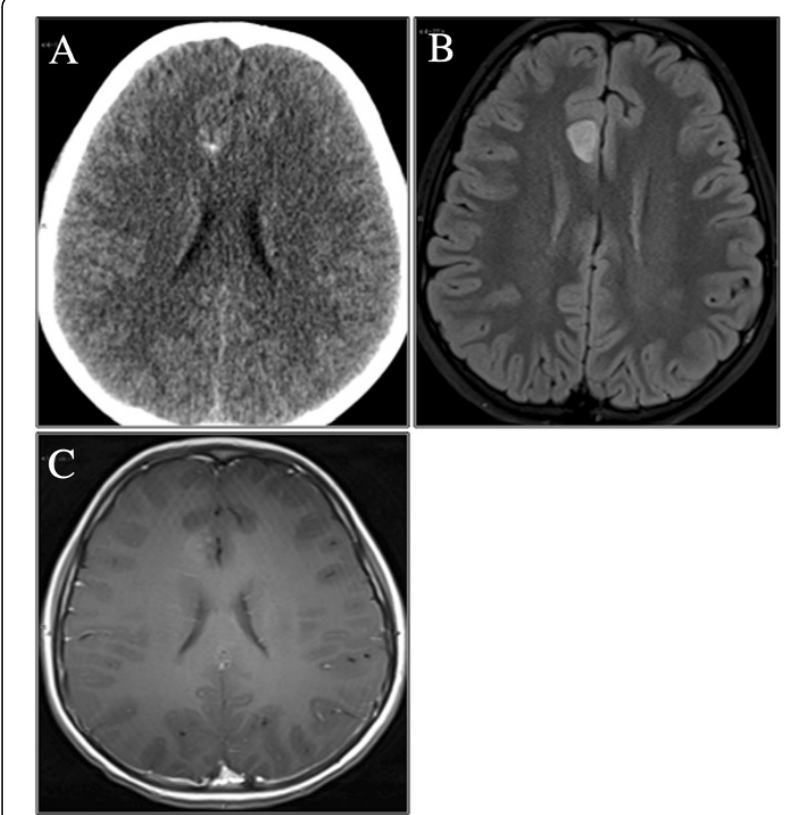

Figure 3 Patient 2: head CT scan and brain MRI, axial images. (A) CT scan: calcified spots inside a right frontomesial mass; (B) FLAIR images: parasagittal mass of the right frontal lobe, involving the anterior part of the cingulated gyrus. No perilesional edema; (C) T1-weighted image: heterogeneous post-contrast enhancement.

\section{Patient 2}

A 10-Year-old male was admitted to our Hospital, suffering from frontal headache and focal seizures with a sudden onset. At 7 years a diagnosis of ADHD was performed, based on clinical evidence of speech and learning delay with attention deficit and anxiety symptoms. Head CT scan revealed a right mesial frontal mass, with calcifications. Brain MRI confirmed the small (12 x $17 \mathrm{~mm})$ parasagittal mass of the right frontal lobe, involving the anterior part of the cingulate gyrus. The lesion demonstrated a heterogeneous post-contrast enhancement on T1-weighted image, while restricted diffusion was observed in the solid component (Figure 3). A video-EEG monitoring documented spikes and slow waves, originating from the right frontal area. Treatment with carbamazepine was started. A diagnosis of EVN (grade II WHO) was performed after a gross total resection. The tumor showed proliferation of small, round, synaptophysinpositive cells with a prevalent ribbon-like pattern of growth and scattered more classical monomorphous areas; MIB-1 was about $3-4 \%$. GFAP staining marked scattered reactive astrocytes (Figure 4). After surgery the patient was seizure free with normal EEG and without additional neurological symptoms. The neurocognitive follow up showed a progressive behavioral improvement with a persistence of affective problems but with a reduction of anxiety disorders.

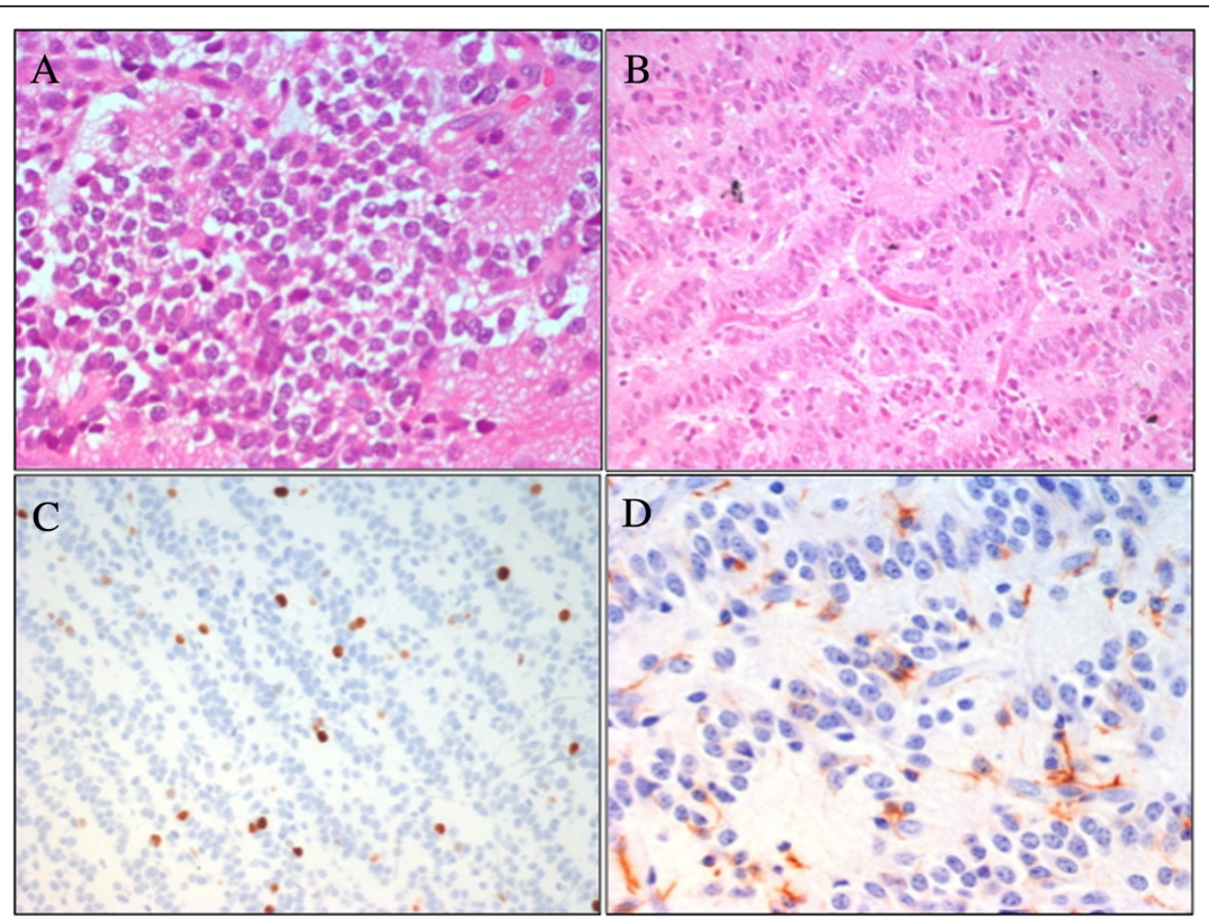

Figure 4 Patient 2: photomicrographs of the extraventricular neurocytoma. (A-B) Small, round, synaptophysin-positive cells, with a prevalent ribbon-like growing pattern and scattered more classical monomorphous areas (hematoxylin and eosin 20x). Photomicrographs of (C) high immunoreactivity to Ki-67 and (D) GFAP stain marked scattered reactive astrocytes. 


\section{Discussion}

Neurocytoma is a rare tumor of the central nervous system, mainly recognized within the ventricular system adjacent to the Monros foramina in middle-aged patients. It displays both neuronal and glial differentiation. Extraventricular neurocytoma was introduced as a separate entity from central neurocytoma in the 2007 World Health Organization (WHO) classification of CNS tumors [2], because of a parenchymal site and a more aggressive neurobiological behaviour. EVN has a marked tendency to glial differentiation [4]. Raised intracranial pressure symptoms are commonly associated to the presence of these lesions, not only due to the size of the lesion but also to the perilesional edema. It can also rarely occur in childhood. Data from the literature about EVNs in the pediatric population, derive almost exclusively from case reports. A literature review about pediatric cases of EVNs included in the PubMed database in the last 20 years identified 29 studies, overall 43 patients [5-8,4,9-14,1,15-31]. Tumor location and presenting symptoms are summarized in Table 1 . Lesions were supratentorial in 32 out of 43 cases $(74 \%)$

Table 1 Summary of demographic data, tumor location and symptoms in pediatric cases of EVNs reported in literature (n.d.: not defined)

\begin{tabular}{|c|c|c|c|c|}
\hline & Authors & Age (years) & Tumor location & Presenting symptoms \\
\hline 1 & Tortori-Donati P et al. [5] & 9 & Temporal & Seizures \\
\hline 2 & Myung JK et al. [6] & 9 & Frontal & Headache \\
\hline 3 & Brat DJ et al. [7] & $\begin{array}{l}\text { From } 5 \text { to } \\
18 \text { (7 patients) }\end{array}$ & Cerebrum & n.d. \\
\hline 4 & Limaiem F et al. [8] & 4 & Cerebral hemisphere & Seizures \\
\hline 5 & Giangaspero F et al. [4] & $\begin{array}{l}\text { From } 5 \text { to } \\
18 \text { (4 patients) }\end{array}$ & $\begin{array}{l}\text { Frontal, occipital, temporal, parietal, } \\
\text { hypothalamus }\end{array}$ & Seizures, dizziness \\
\hline 6 & Agarwal S et al. [9] & 16 & Spinal cord & n.d. \\
\hline 7 & Ahmad F et al. [10] & 15 & Brainstem, cerebellum & Hydrocephalus \\
\hline 8 & Brandis A et al. [11] & 1 & Cerebellum & n.d. \\
\hline 9 & Buchbinder D et al. [12] & 1 & Frontal & n.d. \\
\hline 10 & Cheung YK [13] & n.d. & Thalamus & n.d. \\
\hline 11 & Choi $\mathrm{H}$ et al. [14] & 8 & Frontal & n.d. \\
\hline 12 & Garber ST and Brockmeyer DL [1] & 8 & Frontal & Seizures \\
\hline 13 & Ghosal N et al. [15] & 9 & Frontoparietal & n.d. \\
\hline 14 & Hamilton R [16] & 11 & Frontal & Headache, nausea, vomiting \\
\hline 15 & Harada M et al. [17] & 7 & Frontal & Seizures \\
\hline 16 & Makhdoomi R et al. [18] & 5 & Cerebellar vermis & Headache, vomiting, \\
\hline 17 & Mller-Hartmann W et al. [ 19] & 16 & Parietooccipital & Headache \\
\hline 18 & Mpairamidis E et al. [20] & 3 & Parietotemporal & Seizures \\
\hline 19 & Nishio S et al. [21] & 1 - 2 (2 patients) & Frontal Temporal & Seizures, loss of consciousness, headache \\
\hline 20 & Pal L et al. [22] & 6 & Cerebellar & $\begin{array}{l}\text { Vomiting, headache, cerebellar } \\
\text { symptoms }\end{array}$ \\
\hline 21 & Polli FM et al. [23] & $6-15$ (2 patients) & Spinal cord & $\begin{array}{l}\text { Chronic intracranial hypertension, } \\
\text { paraesthesiae and limb weakness }\end{array}$ \\
\hline 22 & Psarros TG et al. [24] & $1 \mathrm{yr}, 3 \mathrm{mo}$ & Spinal cord & $\begin{array}{l}\text { Somnolence, bilateral sixth nerve palsy, } \\
\text { limb weakness }\end{array}$ \\
\hline 23 & Raja Al et al. [25] & 7 & Occipital & NF1 \\
\hline 24 & Singh A et al. [26] & 8 & Spinal cord & Paraparesis, urinary incontinence \\
\hline 25 & Stapleton SR et al. [27] & 12 & Spinal cord & $\begin{array}{l}\text { Spinal pain, numbness, paraesthesiae } \\
\text { and limb weakness }\end{array}$ \\
\hline 26 & Treier M et al. [28] & 11 & Temporal & Seizures \\
\hline 27 & Yang GF et al. [29] & 2 & Frontal & Hemiparesis \\
\hline 28 & Yi KS et al. [30] & $\begin{array}{l}\text { from } 10 \text { to } \\
13 \text { (4 patients) }\end{array}$ & $\begin{array}{l}\text { Cerebral hemisphere, cerebellum } \\
\text { and thalamus }\end{array}$ & Headache, dizziness, seizures \\
\hline 29 & Han et al. [31] & 2 & Frontal & Vomiting and papilloedema \\
\hline
\end{tabular}


and infratentorial in 5 cases $(11 \%)$. In the remaining six patients $(13 \%)$ the lesion was located in the spinal cord. Among patients with a supratentorial tumor, EVN was located in the frontal lobe in 20 cases $(62.5 \%)$, whereas in the remaining 12 patients $(37.5 \%)$ the tumor location was temporal, parietal, occipital, thalamic or hypothalamic. Age at clinical onset ranged from 1 to 18 years (mean 8.5 yrs). Despite the prevalence of the EVN in the frontal lobe, the seizure activity is the most common presenting symptom, followed by headache and cranial nerve palsy. None of the reported patients had behavioral disorders or ADHD as presenting symptoms. In our patients a diagnosis of ADHD had been made several years earlier than the occurrence of classical symptoms of EVN such headache, vomiting, papilloedema and seizures.

Attention deficit/hyperactivity disorder has to be well defined among the behavioral disorders appearing at school age, in order to avoid misdiagnosis. ADHD defines significant and wide-ranging impairments and affects as many as 3 to $9 \%$ of children worldwide. It is based on strict criteria but is often over-diagnosed. The diagnosis of primary ADHD is made by DSM IV criteria when there is no evidence from the history, the physical examination or laboratory findings of any other condition producing a similar clinical picture. Other psychiatric and neurological disorders such as traumatic brain injury, epilepsy and depression can lead to disturbances in attention and/or activity level. In patients with frontal tumor masses and low proliferation index, the attention impairment and behavioral disorders probably result from direct disruption of frontal lobe functioning or disconnection from subcortical afferents.
Our patients were evaluated with cognitive and behavioral assessment at the time of admission, before and after surgery, with one-year follow-up intervals. Clinical history reported by parents showed that language and motor delay had already been present since they were 4year-old. Therefore we hypothesized a delayed global development, overlooked and underestimated when the ADHD was diagnosed. Cognitive assessment was performed by Wechsler Intelligence Scales for Children (WISC III), documenting a normal range and no significant difference between verbal and performance skills. Behavioral symptoms were clinically investigated and standardized by Child Behavior Checklist (CBCL 6-18) DSM IV oriented, used for children and teenager [32]. Patient 1, preoperatively evaluated, showed an affective $(\mathrm{T}$ score $=70)$ and attention impairment $(\mathrm{T}$ score $=70)$ and a significant anxiety problem $(\mathrm{T}$ score $=73$ ). Postoperative assessment, 14 months after surgery, showed no evidence of symptoms previously reported: affective $(\mathrm{T}$ score $=67)$ and attention impairment $(\mathrm{T}$ score $=59)$ and anxiety problem $(\mathrm{T}$ score $=66)($ Figure 5$)$. Patient 2 showed before surgery affective $(\mathrm{T}$ score $=75)$ and anxiety problem ( $\mathrm{T}$ score $=73$ ); 12 months after surgery there was a persistence of a affective problems $(\mathrm{T}$ score $=75)$ and a lowering of anxiety problem ( $\mathrm{T}$ score $=68$ ) (Figure 6). Both patients showed an affective and attention impairment and significant anxiety. Based on these evaluations a diagnosis of ADHD could not be confirmed. Previous formal testing for ADHD diagnosis was not available at the time of admission in the described cases.

Patient 2 had focal seizures shortly before diagnosis and they stopped after surgery, with normal EEG pre and post-operatively. Moreover, the progressive improvement

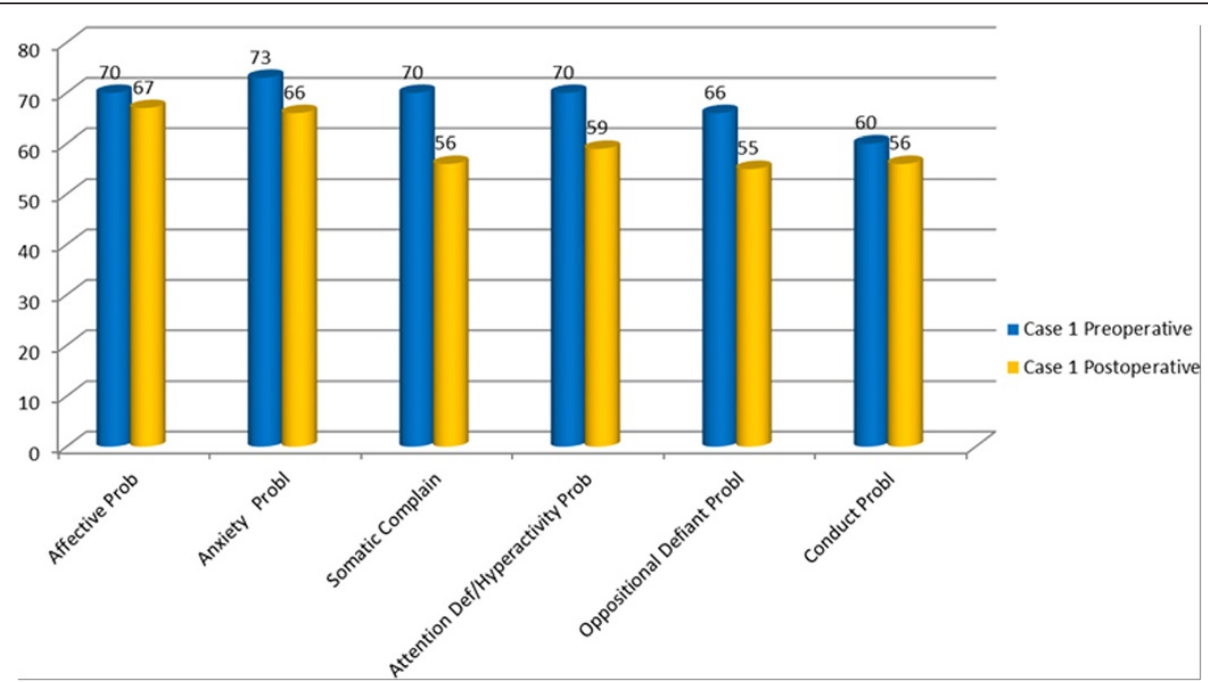

Figure 5 DSM-Oriented scales of the Child Behavior Checklist (CBCL): preoperative and postoperative assessment in the patient 1. T Score $\leq 60$ Range Normal; 61-70 Range Borderline; >70 = Range Clinical. 


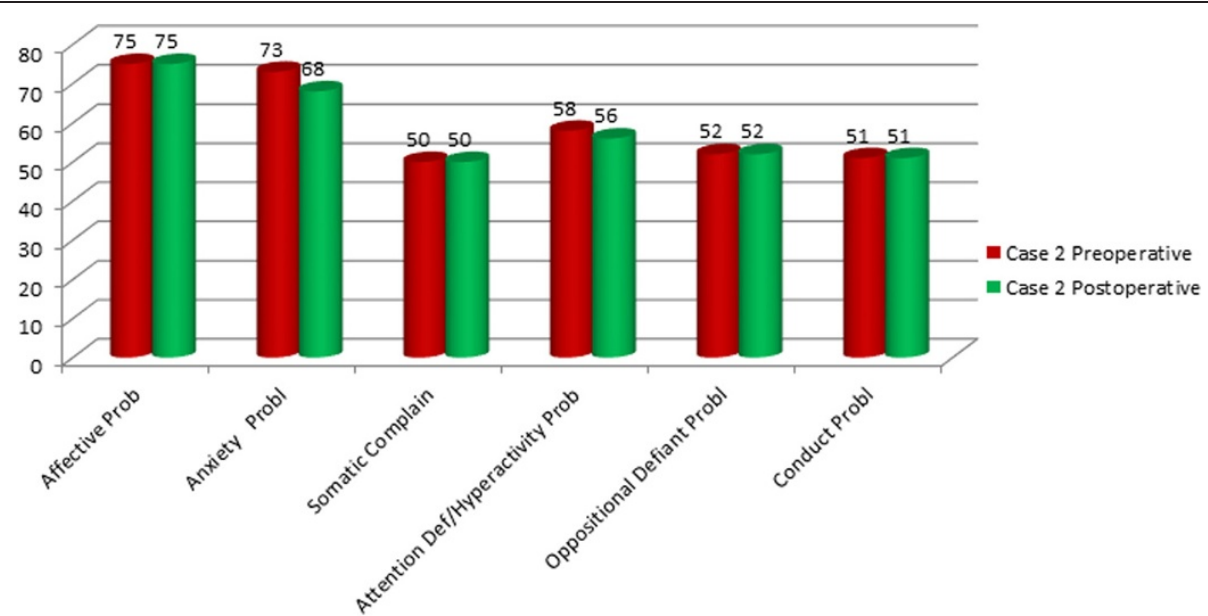

Figure 6 DSM-Oriented scales of the Child Behavior Checklist (CBCL): preoperative and postoperative assessment in the patient 2. T Score $\leq 60$ Range Normal; 61-70 Range Borderline; $>70=$ Range Clinical.

after tumor resection suggests a frontal lobe disfunction as the origin of observed neuro-behavioural symptoms.

Attention deficit hyperactivity disorder is associated with multiple neuropsychological deficits. Several studies underline how difficult it is to make a diagnosis of ADHD. Our experience suggests caution in cases with significant comorbidity before excluding alternative diagnoses.

A recent study, based on electronic records of Emergency Department visits for 87 pediatric patients with brain tumors, retrospectively reviewed from 2002 to 2011, shows that behavior/school change and altered mental status appear with a low frequency, less than 17\% [33]. These data are probably justified by brain plasticity during childhood allowing good compensation of neuro-cognitive impairment and resulting in intracranial hypertension as the most frequent symptom at diagnosis.

Our patients underwent gross total resection. Surgical resection remains the main management strategy for a good outcome. When a subtotal surgical resection is performed, radiotherapy could be considered to ensure better local disease control.

Neuropsychological follow-up one year after resection showed progressive behavioral improvement in both patients, suggesting that the initial diagnosis was not ADHD.

\section{Conclusions}

Attention deficit in childhood, not symptomatic of other injuries, do not tend to improve with age, while an age-related improvement is possible in hyperactivity disorders. We ascribe the improvement of the behavioural performance to the surgical resection, in our patients. This suggests that the attention deficit/hyperactivity disorder was linked to the presence of the EVN. Our report should stimulate clinicians to be careful to the behavioral disorders in childhood not connectable to a clear neuropsychological diagnosis, such as a poor academic achievement and problematic peer relationship, since they could have an organic etiology.

\section{Consent}

Written informed consent was obtained from the patients parents for publication of these Case reports and any accompanying images. A copy of the written consent is available for review by the Editor of this journal.

\section{Abbreviations}

EVN: Extra ventricular neurocytoma; ADHD: Attention deficit/hyperactivity disorder; WISC III: Wechsler intelligence scales for children; CBCL: Child behavior checklist; WHO: World Health Organization.

\section{Competing interests}

The authors declare that they have no competing interests.

\section{Authors contributions}

RM and MGC have made substantial equal contribution to conception and design of the paper; RM, MGC and AM have been involved in drafting the manuscript; SC and DES have been involved in acquisition of neuropsychological data; GSC has been involved in acquisition of neuroimages; FDC carried out the histological analysis; AM, RM and MGC have been involved in analysis and interpretation of data. AC, AM and ER have been involved in revising it critically; AM and CEM have given final approval of the version to be published. All authors read and approved the final manuscript.

\section{Acknowledgements}

We acknowledge patient s family for collaboration.

This work was partially supported by Associazione Genitori Onco-Ematologia Pediatrica Per un sorriso in pi ONLUS.

\section{Author details}

${ }^{1}$ Department of Neuroscience and Neurorehabilitation, Neurosurgery Unit, Bambino Ges Children s Hospital, IRCCS, Piazza Sant Onofrio 4, 00165 Rome, Italy. ${ }^{2}$ Department of Hematology/Oncology and Stem Cell Transplantation, Bambino Ges Children s Hospital, IRCCS, Piazza Sant Onofrio 4, 00165 Rome, Italy. ${ }^{3}$ Department of Neurosciences, Neurology Unit, Bambino Ges Children s Hospital, IRCCS, Piazza Sant Onofrio 4, 00165 Rome, Italy. ${ }^{4}$ Department of Radiology/Neuroradiology Unit, Bambino Ges Children s Hospital, IRCCS, Piazza Sant Onofrio 4, 00165 Rome, Italy. ${ }^{5}$ Department of Anatomical Pathology, Bambino Ges Children s Hospital, IRCCS, Piazza Sant Onofrio 4, 00165 Rome, Italy. 
Received: 19 July 2014 Accepted: 8 December 2014

Published online: 19 December 2014

\section{References}

1. Garber ST, Brockmeyer DL: A rare case of a pediatric extra ventricular neurocytoma: case report and review of the literature. Childs Nerv Syst 2012, 28(2):321 326

2. Louis DN1, Ohgaki H, Wiestler OD, Cavenee WK, Burger PC, Jouvet A, Scheithauer BW, Kleihues P: The 2007 WHO classification of tumours of the central nervous system. Acta Neuropathol 2007, 114(2):97 109.

3. Mut M1, Gler-Tezel G, Lopes MB, Bilginer B, Ziyal I, Ozcan OE: Challenging diagnosis: oligodendroglioma versus extraventricular neurocytoma. Clin Neuropathol 2005, 24(5):225 229.

4. Giangaspero F, Cenacchi G, Losi L, Cerasoli S, Bisceglia M, Burger PC: Extraventricular neoplasms with neurocytoma features. A clinicopathological study of 11 cases. Am J Surg Pathol 1997, 21:206 212

5. Tortori-Donati P, Fondelli MP, Rossi A, Cama A, Brisigotti M, Pellican G: Extraventricular neurocytoma with ganglionic differentiation associated with complex partial seizures. AJNR Am J Neuroradiol 1999, 20:724 727.

6. Myung JK, Cho HJ, Park CK, Chung CK, Choi SH, Kim SK, Park SH: Clinicopathological and genetic characteristics of extraventricular neurocytomas. Neuropathology 2013, 33:111 121.

7. Brat DJ, Scheithauer BW, Eberhart CG, Burger PC: Extraventricular neurocytomas: pathologic features and clinical outcome. Am J Surg Pathol 2001, 25:1252 1260

8. Limaiem F, Bellil S, Chelly I, Mekni A, Bellil K, Jemel H, Haouet S, Zitouna M, Kchir N: Extraventricular neurocytoma in a child mimicking oligodendroglioma: a diagnostic pitfall. Pathologica 2009, 101:105 107.

9. Agarwal S, Sharma MC, Sarkar C, Suri V, Jain A, Sharma MS, Ailawadhi P, Garg A, Mallick S: Extraventricular neurocytomas: a morphological and histogenetic consideration. A study of six cases. Pathology 2011 43:327 334

10. Ahmad F, Rosenblum MK, Chamyan G, Sandberg Dl: Infiltrative brainstem and cerebellar neurocytoma. J Neurosurg Pediatr 2012, 10:418 422

11. Brandis A, Heyer R, Hori A, Walter GF: Cerebellar neurocytoma in an infant: an important differential diagnosis from cerebellar neuroblastoma and medulloblastoma? Neuropediatrics 1997, 28:235 238

12. Buchbinder D, Danielpour M, Yong WH, Salamon N, Lasky J: Treatment of atypical central neurocytoma in a child with high dose chemotherapy and autologous stem cell rescue. J Neurooncol 2010, 97:429 437.

13. Cheung YK: Central neurocytoma occurring in the thalamus: CT and MRI findings. Australas Radiol 1996, 40:182 184.

14. Choi H, Park SH, Kim DG, Paek SH: Atypical extraventricular neurocytoma. J Korean Neurosurg Soc 2011, 50:381 384.

15. Ghosal N, Dadlani R, Somorendra Singh S, Hegde AS: Atypical extraventricular neurocytoma: a rare and challenging case diagnosed on intraoperative cytology. Cytopathology 2012, 23:270 273.

16. Hamilton R: Case of the month. August 1996 - frontal lobe tumor in 11 year old girl. Brain Pathol 1997, 7:713 714.

17. Harada M, Morioka T, Nishio S, Fukui M: Neurocytoma in the left frontal lobe. No Shinkei Geka 1991, 19:89 92 (In Japanese).

18. Makhdoomi R, Malik NK, Wani A, Bhat S, Baba K: Extraventricular neurocytoma of the vermis in a child. J Clin Neurosci 2010, 17:1469 1471.

19. Mller-Hartmann W, Krings T, Brunn A, Korinth M, Thron A: Proton magnetic resonance spectroscopy of neurocytoma outside the ventricular region - case report and review of the literature. Neuroradiology 2002, 44:230 234.

20. Mpairamidis E, Alexiou GA, Stefanaki K, Sfakianos G, Prodromou N: Extraventricular neurocytoma in a child: case report and review of the literature. J Child Neurol 2009, 24(4):491 4.

21. Nishio S, Takeshita I, Kaneko Y, Fukui M: Cerebral neurocytoma. A new subset of benign neuronal tumors of the cerebrum. Cancer 1992, 70:529 537.

22. Pal L, Santosh V, Gayathri N, Das S, Das BS, Jayakumar PN, Shankar SK Neurocytoma/rhabdomyoma (myoneurocytoma) of the cerebellum. Acta Neuropathol 1998, 95:318 323

23. Polli FM, Salvati M, Miscusi M, Delfini R, Giangaspero F: Neurocytoma of the spinal cord: report of three cases and review of the literature. Acta Neurochir (Wien) 2009, 151:569 574

24. Psarros TG, Swift D, Mulne AF, Burns DK: Neurocytoma-like neoplasm of the thoracic spine in a 15-month-old child presenting with diffuse leptomeningeal dissemination and communicating hydrocephalus. Case report J Neurosurg 2005, 103(2 Suppl):184 190.

25. Raja Al, Yeaney GA, Jakacki Rl, Hamilton RL, Pollack IF: Extraventricular neurocytoma in neurofibromatosis Type 1: case report. J Neurosurg Pediatr 2008, 2:63 67.

26. Singh A, Chand K, Singh H, Sarkar C, Sharma MC: Atypical neurocytoma of the spinal cord in a young child. Childs Nerv Syst 2007, 23:207 211.

27. Stapleton SR, David KM, Harkness WF, Harding BN: Central neurocytoma of the cervical spinal cord. J Neurol Neurosurg Psychiatry 1997, 63:119.

28. Treier M, Doostkam S, Meckel S: Extraventricular neurocytoma: a rare cause of temporal lobe epilepsy. Rofo 2011, 183:1065 1066 (In German).

29. Yang GF, Wu SY, Zhang LJ, Lu GM, Tian W, Shah K: Imaging findings of extraventricular neurocytoma: report of 3 cases and review of the literature. AJNR Am J Neuroradiol 2009, 30:581 585.

30. Yi KS, Sohn CH, Yun TJ, Choi SH, Kim JH, Han MH, Park CK, Park SH, Chang $\mathrm{KH}$ : MR imaging findings of extraventricular neurocytoma: a series of ten patients confirmed by immunohistochemistry of IDH1 gene mutation. Acta Neurochir (Wien) 2012, 154:1973 1980.

31. Han L, Niu H, Wang J, Wan F, Shu K, Ke C, Lei T: Extraventricular neurocytoma in pediatric populations: $A$ case report and review of the literature. Oncol Lett 2013, 6(5):1397 1405.

32. Aebi M, Winkler Metzke C, Steinhausen HC: Accuracy of the DSM-oriented attention problem scale of the child behavior checklist in diagnosing attention-deficit hyperactivity disorder. J Atten Disord 2010, 13(5):454 463.

33. Jackson Lanphear MD, Syana Sarnaik MD: Presenting symptoms of pediatric brain tumors diagnosed in the emergency department. Pediatr Emerg Care 2014, 30(2):77 80.

doi:10.1186/s12883-014-0242-8

Cite this article as: Messina et al:: Behavioral disorders as unusual presentation of pediatric extraventricular neurocytoma: report on two cases and review of the literature. BMC Neurology 2014 14:242.

\section{Submit your next manuscript to BioMed Central and take full advantage of:}

$\otimes$ Convenient online submission

$\otimes$ Thorough peer review

$\nabla$ No space constraints or color $\nabla$ gure charges

$\otimes I m m e d i a t e$ publication on acceptance

\Inclusion in PubMed, CAS, Scopus and Google Scholar

$\otimes$ Research which is freely available for redistribution

Submit your manuscript at www.biomedcentral.com/submit
C) Biomed Central 